\title{
Fenóis totais, atividade antioxidante e inibição da enzima tirosinase de extratos de Myracrodruon urundeuva Fr. All. (Anacardiaceae)
}

VIEIRA, L. M.."; CASTRO, C.F.S.'; DIAS, A.L.B.'; SILVA, A.R. ${ }^{1}$

'Laboratório de Química Tecnológica, Instituto Federal de Educação, Ciência e Tecnologia câmpus Rio Verde, Rodovia Sul Goiano, CEP 7590-000 - Rio Verde-Brasil *Autor para correspondência: leticiamv18@hotmail.com

RESUMO: Os radicais livres e outros oxidantes demonstram ser parcialmente responsáveis pelo envelhecimento e pelas doenças degenerativas associadas à produção de espécies reativas de oxigênio. Além disto, os compostos fenólicos são reconhecidamente detentores de elevada atividade antioxidante, que geralmente estão envolvidos em tratamentos de problemas de pigmentação da pele, que resultam em hiperpigmentações. Sendo assim este trabalho foi realizado para avaliar o conteúdo de fenóis totais, atividade antioxidante e a capacidade de inibição da tirosinase dos extratos das folhas e cascas do caule da espécie Myracrodruon urundeuva Fr. All. Para determinação do conteúdo de fenóis totais dos extratos orgânicos de M. urundeuva utilizou-se o reativo Folin-Ciocalteau, na avaliação da atividade antioxidante empregando o radical livre DPPH, enquanto que os testes de inibição da enzima tirosinase foram realizados utilizando L-tirosina. A concentração de fenóis totais foi de $77 \mathrm{mg} \mathrm{EAG} \mathrm{g}^{-1} \mathrm{e}$ $194 \mathrm{mg} \mathrm{EAG} \mathrm{g}^{-1}$ nos extratos hexânico e metanólico das folhas e de $45 \mathrm{mg} \mathrm{EAG} \mathrm{g}^{-1}$ e $193 \mathrm{mg}$ EAG g-1 nos extratos hexânico e metanólico das cascas do caule. O potencial antioxidante dos extratos indicaram que o extrato metanólico das cascas do caule $\left(10,9 \pm 0,5 \mu \mathrm{g} \mathrm{mL}^{-1}\right)$, em comparação ao hexânico $(12,9 \pm 0,2 \mu \mathrm{g} \mathrm{mL}-1)$ e ao BHT $\left(220 \pm 7,0 \mu \mathrm{g} \mathrm{mL}^{-1}\right)$, possui atividade antioxidante levemente mais acentuada. No ensaio de inibição da tirosinase, o extrato metanólico das cascas do caule demonstrou a inibição da enzima em $42 \%$ após uma hora.

Palavras-chave: compostos fenólicos, DPPH, hiperpigmentação, tirosinase.

\begin{abstract}
Total phenolics, antioxidant activity and tyrosinase enzyme inhibition by Myracrodruon urundeuva Fr. All. (Anacardiaceae) extracts. Free radicals and other oxidants had demonstrated to be partially responsible for aging and for degenerative diseases associated with the production of reactive oxygen species. In addition, the phenolic compounds are recognized as holders of high antioxidant activity, which usually are involved in the treatment of pigmentation problems, resulting in hyper pigmentation. So this study was carried out in order to evaluate the content of total phenols, antioxidant activity and capacity inhibition of tyrosinase in extracts from leaves and stem barks of the species Myracrodruon urundeuva Fr. All. In order to determine the content of total phenols from organic extracts of $M$. urundeuva, a Folin-Ciocalteau reagent was employed in the evaluation of antioxidant activity, using the DPPH free radical, while the enzyme tyrosinase inhibition tests were performed using L-tyrosine. The amount of total phenols was $77 \mathrm{mg} \mathrm{EAG} \mathrm{g}^{-1}$ and 194 in the hexane and methanolic extracts from the leaves and $45 \mathrm{mg} \mathrm{EAG} \mathrm{g}^{-1}$ and $193 \mathrm{mg} \mathrm{EAG} \mathrm{g}^{-1} \mathrm{in}$ the hexane and methanolic extracts of the stem barks. The antioxidant potential of extracts indicated that the methanolic extract of stem bark $\left(10.9 \pm 0.5 \mu \mathrm{g} \mathrm{mL}^{-1}\right)$, when compared to the hexane $\left(12.9 \pm 0.2 \mu \mathrm{g} \mathrm{mL}^{-1}\right)$ and BHT $(220 \pm$ $7.0 \mu \mathrm{g} \mathrm{mL}-1$ ), presented a slightly higher antioxidant activity. For the tyrosinase inhibitiontrial , the methanolic extract ofstem barks indicated anenzyme inhibition of $42 \%$ after an hour.
\end{abstract}

Keywords: phenolics compounds, DPPH, hyperpigmentation, tyrosinase.

\section{INTRODUÇÃO}

A rica biodiversidade do Brasil se distribui em diferentes regiões, dentre elas o Cerrado que é um tipo fitofisionômico de vegetação, e está localizado basicamente no Planalto Central do Brasil. Considerado o segundo maior bioma do país, este abrange $21 \%$ do território brasileiro e 
possui uma vasta flora endêmica, com mais de 500 espécies medicinais as quais são largamente utilizadas pela população brasileira (Borlaug, 2002).

Dentre as espécies nativas do cerrado, encontra-se Myracrodruon urundeuva Fr. All. Pertencente à família Anacardiaceae é uma espécie tropical dióica, popularmente conhecida como aroeira-do-campo, aroeira-preta ou urundeuva, que se distribui nas regiões Nordeste, Sudeste e Centro-Oeste (Almeida et al., 1998). A árvore é caducifólia, atinge de 5 a $20 \mathrm{~m}$ de altura e 30 a $60 \mathrm{~cm}$ de DAP (diâmetro a altura do peito, 1,30 m do solo) (Carvalho, 2003). Geralmente, a espécie floresce entre julho e setembro, e a maturação dos frutos ocorre de setembro a outubro (Lorenzi, 1992).

Sua utilização se aplica ao fornecimento de madeira, como planta medicinal e na indústria de curtimento de couro (Andrade et al., 2000). A madeira, muito utilizada na construção civil, apresenta grande resistência mecânica e é praticamente imputrescível (Queiroz et al., 2002). Seu potencial farmacológico e uso popular surgem como uma alternativa terapêutica. Atribuído, sobretudo a folhas e cascas do caule, as propriedades medicinais da aroeira-preta se aplicam ao tratamento das afecções urinárias, respiratórias, ação antiinflamatória e cicatrizante (Andrade et al., 2000).

A casca da aroeira-preta é muito rica em taninos e outras compostos fenólicos, contendo também, flavonóides, taninos e seus percussores, além de duas chalconas dimétricas (Matos, 2002).

A utilização da Myracrodruon urundeuva Fr. Al. abrange diversas possibilidades, possuindo inclusive propriedades antivirais e, em certa medida, validando assim os seus usos tradicionais na medicina popular (Cecílio et al., 2012).

Os compostos fenólicos incluem mais de oito mil estruturas químicas que podem ser classificados pelo número e arranjo de seus átomos de carbono, sendo divididos em pelo menos dez grupos, a saber: fenóis simples, ácidos fenólicos, cumarinas, isocumarinas, naftoquinonas, xantonas, estilbenes, antraquinonas, flavonóides e ligninas (Crozier et al., 2009).

Diversos pesquisadores têm realizado estudos biológicos e farmacológicos de compostos fenólicos (Vicente, et al, 2014; Scherer \& Godoy, 2014). Esses estudos têm ampliado as propriedades farmacológicas desses compostos, uma delas é a atividade antioxidante (Okuda \& Ito, 2011). Várias substâncias fenólicas são importantes antioxidantes, uma vez que possuem esqueleto carbônico propício para a estabilização de radicais livres (Larrauri et al., 1996). Tratamentos efetivos contra doenças cardiovasculares e certos tipos de câncer estão sendo realizados utilizando fontes de fitoquímicos em particular os compostos fenólicos (Junior et al.,
2014).

Lachman et al. (2010) mostraram que uma grande variedade de fontes vegetais biossintetizam compostos que possuem atividade antioxidante e podem ser utilizados como uma fonte natural de substâncias que possuem a capacidade de sequestrar os radicais livres. Os extratos cuja composição possuem compostos fenólicos antioxidantes são de particular interesse para a indústria de conservantes de alimentos.

Estudos têm demonstrado que os radicais livres são os principais causadores de diversas doenças degenerativas, tais como doenças cardiovasculares, neurológicas e algumas formas de câncer (Prior et al., 1998). Os antioxidantes presentes nas plantas podem atuar como agentes redutores, seqüestradores de radicais livres, inibidores de enzimas e como quelantes de metais (Wang \& Lin, 2000).

Atualmente existe um grande número de plantas medicinais cujo potencial terapêutico tem sido estudado em uma variedade de modelos experimentais, e cujos mecanismos de ação têm sido investigados quanto à atividade de inibição enzimática. Estes estudos têm providenciado informações úteis para o desenvolvimento de novas farmacoterapias a partir dessas plantas para o tratamento de várias patologias (Sousa et al., 2008).

Uma dessas patologias é a hiperpigmentação da pele, que pode ser dependente tanto de um aumento do número de melanócitos quanto da atividade melanogênica de enzimas, como a tirosinase. A tirosinase (EC 1.14.18.1) é a enzima chave na produção de melanina em mamíferos. Esta atua oxidando monofenóis à orto-difenóis e estes à ortoquinonas. Seu substrato principal em mamíferos é o aminoácido tirosina que é oxidado à L-DOPA (L-3,4-diidroxifenilalanina) e este após diversas reações químicas e enzimáticas polimeriza-se formando a melanina (Sánchez-Ferrer et al., 1995).

A melanina é um biopolímero heterogêneo, pigmentado polifenólico de alto peso molecular, desempenha um papel importante na proteção da pele humana dos efeitos nocivos da radiação UV do sol, sendo responsável pela cor da pele, do cabelo e dos olhos (Chang, 2009; Passeron et al., 2005).

Em função de desenvolver terapias ou profilaxias para tratar ou prevenir desordens de hiperpigmentação, a inibição da atividade da tirosinase tem sido geralmente o alvo. Há muitas formas de realizar essas terapias, como mecanismos competitivos ou não competitivos que interferem na atividade catalítica da tirosinase, por exemplo, interrupção da maturação ou diminuição da estabilidade da tirosinase, os quais reduziriam a síntese e deposição de melanina (Ando et al., 2007).

O desenvolvimento e a caracterização 
de novos inibidores da enzima tirosinase são extremamente úteis, devido a seus potenciais para aplicações na prevenção de hipercromias. Dessa forma, tornam-se necessárias pesquisas de agentes despigmentantes que inibem a tirosinase, sendo de extrema importância a descoberta de substâncias naturais obtidas através de extratos de plantas, com tal propriedade (Macrini et al., 2009; Sousa, 2011).

Considerando que a aroeira-preta apresenta características medicinais, alimentícias, ornamentais e industriais reunindo em única espécie um potencial múltiplo de aplicações e que se trata de espécie ainda muito pouco estudada, objetivou-se neste trabalho determinar os fenóis totais, a atividade antioxidante e a capacidade de inibição da tirosinase presentes na espécie Myracrodruon urudeuva Fr. All. conhecida popularmente como aroeira-preta.

\section{MATERIAL E MÉTODOS}

Os experimentos foram conduzidos no Laboratório de Química Tecnológica, do Instituto Federal Goiano, câmpus Rio Verde, no município de Rio Verde, Goiás, Brasil.

\section{Material Vegetal}

A coleta da parte aérea e cascas do caule de M. urundeuva Fr. All. foi realizada na unidade de conservação do campus da FESURV - Universidade de Rio Verde na Fazenda Fontes do Saber $\left(17^{\circ} 46^{\prime} 29,6^{\prime \prime}\right.$ e e $\left.50^{\circ} 57^{\prime} 34,8^{\prime \prime} W\right)$ e identificada por comparação no Herbário Jataiense da Universidade Federal de Goiás, Jataí, GO (exsicata HJ 5612).

Após a coleta, o material vegetal foi seco em estufa com circulação de ar à $40^{\circ} \mathrm{C}$ por 48 horas. Em seguida, as folhas e cascas do caule foram trituradas até a obtenção de um pó homogêneo e armazenadas sob refrigeração até o seu uso.

\section{Preparação dos Extratos}

Inicialmente foi usado hexano, na proporção de $50 \mathrm{~g}$ do material vegetal (folhas e cascas do caule, em frascos separados) para $500 \mathrm{~mL}$ do solvente durante dois dias, obtendo-se uma solução heterogênea. Em seguida a solução foi filtrada. O filtrado, agrupado e evaporado, resultou nos extratos de $M$. urundeuva hexânico das folhas (MUHF) e cascas do caule (MUHC). O resíduo vegetal foi então extraído com metanol usando a mesma proporção acima, fornecendo os extratos de M. urundeuva metanólico das folhas (MUMF) e das cascas do caule (MUMC). O rendimento dos extratos foi expresso em percentagem em relação a massa seca do material vegetal.

\section{Determinação de Fenóis Totais}

O teor de fenóis totais dos extratos de
M. urundeuva Fr. All. foi analisado, utilizando ácido gálico como padrão pelo método de FolinCiocalteau, com algumas modificações. O método de Folin-Ciocalteau baseia-se na transferência de um elétron, medindo assim a capacidade redutora do antioxidante em estudo. As vantagens desse método são a disponibilidade comercial dos reagentes, a absorção do grupo cromóforo em 730 nm, o que reduz a interferência de substâncias coradas presentes na amostra, o grande número de dados disponíveis na literatura e a praticidade de implantação, uma vez que se trata de um ensaio simples, rápido, barato e robusto (Prior et al., 1998).

Soluções metanólicas e hexânicas de extratos das folhas e cascas do caule de $M$. urundeuva $\left(2,5 \mathrm{mg} \mathrm{mL}^{-1}\right)$ foram preparadas. A cada tubo, misturou-se $250 \mu \mathrm{L}$ de reagente de FolinCiocalteau (diluído em água 1:1), $500 \mu \mathrm{L}$ de solução saturada de $\mathrm{Na}_{2} \mathrm{CO}_{3}$, e $4 \mathrm{~mL}$ de água destilada. As soluções foram incubadas no escuro à temperatura ambiente durante $25 \mathrm{~min}$. A absorbância da amostra foi lida frente ao branco a $725 \mathrm{~nm}$ usando um espectrofotômetro (Biospectro, modelo SP220). O teor de fenóis totais (FT) dos extratos foi determinado por comparação com uma curva de calibração de ácido gálico, como um padrão cuja concentração de Abs = 0,0628 x (Conc Ácido Gálico, $\mu \mathrm{g} \mathrm{mL}-1)-0,0521, r^{2}=0,9973$ e representadas como equivalentes de ácido gálico por grama de extrato (mg EAG). As análises foram realizadas em triplicata.

\section{Determinação da Atividade Antioxidante - Método do radical DPPH}

A atividade antioxidante foi medida segundo o método descrito por Melo et al. (2006), usando o radical livre estável DPPH, com algumas modificações, monitorando-se o consumo do radical livre DPPH pelas amostras, através da medida do decréscimo da absorbância de soluções de diferentes concentrações. Resumidamente, vários volumes de solução de extratos de folhas e cascas do caule de $M$. urundeuva $\left(1,0 \mathrm{mg} \mathrm{mL}^{-1}\right)$ foram adicionados a $2,0 \mathrm{~mL}$ de solução metanólica de DPPH $\left(0,1191 \mathrm{mmol} \mathrm{L}^{-1}\right)$ e mantidos no escuro durante $30 \mathrm{~min}$ à temperatura ambiente. Em seguida, a absorbância foi medida a $517 \mathrm{~nm}$. O metanol foi utilizado como controle negativo e o BHT (butil-hidróxi-tolueno) foi usado como um padrão positivo. Os resultados foram expressos pelo valor $\mathrm{CE}_{50}$ (Concentração Efetiva 50\%), que determina a concentração de extrato $(\mu \mathrm{g} \mathrm{mL}-1)$, que proporciona uma inibição de $50 \%$; quanto mais baixo o seu valor, maior é a eficiência do antioxidante. A capacidade de eliminação do radical DPPH foi calculada através da equação abaixo (percentagem de inibição do radical DPPH). 


$$
\% \text { de inibição do } D P P H^{*}=\frac{\left(A b s_{D P P H} \cdot-A b s_{a m o s t r a}\right)}{A b s_{D P P H} \cdot} \times 100
$$

Todas as medidas foram realizadas em três experimentos independentes, cada um em triplicata, e os resultados foram expressos em $\mu \mathrm{g} \mathrm{mL}^{-1} \mathrm{com}$ média e desvio padrão.

\section{Tirosinase \\ Procedimento para Ensaio de Inibição da}

A tirosinase de cogumelo e a L-tirosina foram adquiridos da Sigma Chemical Co e Vetec, respectivamente. A atividade da tirosinase foi determinada por espectrofotometria, realizada conforme descrito por Khatib (2005), com adaptações em nosso laboratório. De forma geral, foram preparadas três soluções: solução A: contendo $500 \mu \mathrm{L}$ de tampão fosfato ( $\mathrm{pH} 7,0), 2 \mathrm{~mL}$ da tirosinase de cogumelo (200 U mL-1) e $50 \mu \mathrm{L}$ da amostra da solução com extrato etanólico da planta $(1000 \mu \mathrm{g} \mathrm{mL}-1)$; solução B: (controle negativo) $500 \mu \mathrm{L}$ de tampão fosfato $(\mathrm{pH} 7,0), 2,0 \mathrm{~mL}$ da tirosinase de cogumelo (200 U mL-1) e $50 \mu \mathrm{L}$ de etanol; solução C: (controle positivo) $500 \mu \mathrm{L}$ de tampão fosfato $(\mathrm{pH} 7,0), 2,0 \mathrm{~mL}$ da tirosinase de cogumelo (200 $\mathrm{U} \mathrm{mL}^{-1}$ ) e $50 \mu \mathrm{L}$ de ácido Kójico $(1000 \mu \mathrm{g} \mathrm{mL-1})$. Após 5 minutos, 2,0 $\mathrm{mL}$ de solução de $2 \mathrm{mM}$ de L-tirosina foi adicionado a cada solução teste. A absorção a $475 \mathrm{~nm}$ foi monitorada em função do tempo, realizando-se a leitura após 60 minutos. A variação da densidade ótica foi comparada na presença e ausência dos extratos para verificar a inibição da tirosinase (Khatib et al, 2005).

\section{Análise Estatística}

Os resultados foram apresentados como médias e desvios padrão de três ensaios independentes $(n=3)$. O programa estatístico utilizado foi o Assistat 7.6 Beta. Dados com $p<0,01$ foram considerados significativos.

\section{RESULTADO E DISCUSSÃO}

O método de Folin-Ciocalteau permitiu quantificar compostos fenólicos presentes nas amostras. A Tabela 1 demonstra a quantidade total de fenóis dos extratos provenientes de cada fração das folhas e cascas do caule obtidas por extração hexânica e metanólica. A extração metanólica das folhas e cascas do caule de $M$. urundeuva apresentou os maiores conteúdos de fenóis totais, com teores de 194 e 193 mg EAG g$^{-1}$, respectivamente, destacando assim as características individuais que cada espécie de planta tem de armazenamento de compostos como os fenóis totais, podendo estar presente uniformemente em diferentes locais das plantas ou somente em áreas específicas. Os compostos fenólicos são substâncias bioativas possuindo um grande grupo diversificado de metabólitos secundários que são amplamente distribuídos em todas as plantas (Hatamnia et al., 2014). Já a extração hexânica das folhas e cascas do caule apresentou menores concentrações de fenóis, 77 e $45 \mathrm{mg} \mathrm{EAG} \mathrm{g}^{-1}$. O solvente hexânico é apolar enquanto o metanólico é polar, os extratos com concentrações de fenóis diferentes se dão devido á grupos de compostos distintos que se ligam com o solvente de acordo com as características de polaridade.

Procurou-se, também, avaliar a atividade antioxidante dos extratos $M$. urundeuva, pois os resultados antioxidantes positivos podem indicar a existência de outros tipos de atividades, como por exemplo, a bactericida e a antiinflamatória (PaulaJunior et al., 2006).

A capacidade de seqüestrar radicais livres em relação ao radical estável 2,2-difenil-1-picrilhidrazil (DPPH) foi inicialmente escolhida por se tratar de uma metodologia simples, rápida e sensitiva, muito conveniente para realização de "screening" de um grande número de amostras com diferentes polaridades (Koleva et al., 2002).

TABELA 1. Teor de Fenóis Totais (FT) expressos com equivalentes de ácido gálico (EAG).

\begin{tabular}{ccc}
\hline & \multicolumn{2}{c}{ FT (mg EAG g-1 ms \pm DP) } \\
\cline { 2 - 3 } Amostra & Extração \\
\cline { 2 - 3 } & $77 \pm 11 \mathrm{a}$ & Metanólica \\
\hline Folhas & $45 \pm 20 \mathrm{a}$ & $194 \pm 15 \mathrm{~b}$ \\
Cascas do caule & $193 \pm 33 \mathrm{~b}$ \\
\hline
\end{tabular}

Os valores expressam a média e o desvio padrão de três repetições. ms : massa seca de material vegetal. Letras minúsculas idênticas indicam equivalência estatística ao nível de $1 \%$ de probabilidade $(p<0,01)$. 
O potencial dos diferentes extratos metanólicos de $M$. urundeuva em sequestrar radicais livres foi expresso como concentração final do extrato necessária para inibir a oxidação do radical DPPH em $50 \%$, e os resultados são descritos na Tabela 2.

TABELA 2. Atividade Antioxidante dos extratos metanólicos de $\mathrm{M}$. urundeuva frente ao radical livre DPPH (CE50)

\begin{tabular}{lc}
\hline & CE $50\left(\mathrm{ug} \mathrm{mL}^{-1}\right)$ \\
\cline { 2 - 2 } Folhas & $12,9 \pm 0,2 \mathrm{a}$ \\
Cascas do caule & $10,9 \pm 0,5 \mathrm{~b}$ \\
BHT & $220 \pm 7,0 \mathrm{c}$ \\
\hline
\end{tabular}

Os valores expressam a média e o desvio padrão de três repetições.. Letras minúsculas idênticas indicam equivalência estatística ao nível de $1 \%$ de probabilidade $(p<0,01)$.

As substâncias antioxidantes presentes nos extratos reagem com o DPPH que é um radical estável, e converte-o em 2,2-difenil-1-picrilhidrazina. O grau de descoloração indica o potencial antioxidante do extrato. Um extrato que exibe alto potencial em seqüestrar radicais livres possui valor de $\mathrm{CE}_{50}$ baixo. Desta forma, uma pequena quantidade de extrato é capaz de decrescer a concentração inicial do radical DPPH em $50 \%$, ou seja, inibir a oxidação do radical em $50 \%$.

Os menores valores de $\mathrm{CE}_{50}$ foram obtidos pelo extrato metanólico das cascas do caule $(10,9 \mu \mathrm{g}$ $\left.\mathrm{mL}^{-1}\right)$, extrato metanólico das folhas $\left(12,9 \mu \mathrm{g} \mathrm{mL}^{-1}\right)$ e BHT $\left(220 \mu \mathrm{g} \mathrm{mL}^{-1}\right)$, respectivamente. Conforme relatado na determinação de compostos fenólicos, os extratos metanólicos das folhas e cascas do caule apresentaram alto conteúdo de fenóis e conseqüentemente bons potenciais para seqüestrar radicais livres, justificando o fato de a atividade antioxidante ter sido realizada somente com extratos polares.

A relação entre concentração de fenóis totais e a capacidade de seqüestrar radicais livres dos extratos parece ser bastante significativa, visto que extratos com maior conteúdo de fenóis totais são justamente os extratos com maior atividade antioxidante. Os extratos hexânicos de $M$. urundeuva mostraram ter, no melhor dos casos, baixo conteúdo de fenóis totais, quando comparados com os extratos metanólicos, relacionando então com a possibilidade de não apresentarem capacidade de capturar radicais livres nas condições empregadas, sugerindo então que os compostos secundários com atividade antioxidante concentram-se preferencialmente nos extratos polares das folhas e cascas do caule de M. urundeuva.

Alguns autores mostram que compostos fenólicos produzidos por plantas podem interagir com a tirosinase inibindo-a ou ativando-a (Okombi et al, 2006). Existem relatos de que compostos fenólicos podem ser usados como agentes despigmentantes, pelo fato de possuírem em sua estrutura química, compostos semelhantes ao da tirosina, o substrato da tirosinase (Boissy \& Manga, 2004). Portanto, a ação das substâncias utilizadas como agentes despigmentantes da pele, deve-se em parte, à ação de componentes fenólicos (Rao, 2003).

A porcentagem de inibição sobre a enzima foi calculado comparando-se a absorbância das amostras (ensaio contendo extrato + enzima + subtrato) com a do controle da enzima (ensaio contendo tampão + enzima + substrato). Os valores correspondentes à absorbância do controle da enzima forneceram o referencial da atividade máxima da enzima utilizada para a realização dos experimentos, ou seja, refere-se à capacidade da enzima para a formação dos produtos a partir dos seus substratos, considerando a atividade máxima da enzima igual a $100 \%$. Sendo assim, as porcentagens de inibição das amostras foram calculadas de acordo com a seguinte equação: \% inibição $=[(C-A) \times 100] / C$, onde $C$ representa a absorbância do controle da enzima, subtraída do branco do substrato e A representa a absorbância da amostra subtraída do branco do extrato (extrato vegetal + substrato + tampão).

A Tabela 3 mostra a porcentagem de ativação/inibição da tirosinase, onde a enzima pura obteve $100 \%$ de ativação após uma hora. O controle positivo usado foi o inibidor comercial da tirosinase, ácido kójico.

Os resultados demonstraram que ambos os extratos foram capazes de influenciar na atividade enzimática da tirosinase. Os extratos metanólicos das folhas e cascas do caule de $M$. urundeuva foram significativos, apresentando percentuais de inibição da tirosinase de $66 \%$ para o extrato metanólico das folhas e $42 \%$ para o extrato metanólico das cascas do caule, respectivamente, observando que o extrato metanólico das cascas do caule foi mais eficaz na inibição da tirosinase. Essa espécie pode representar um potencial recurso de novos compostos inibidores da tirosinase. Os extratos metanólicos da casca e folhas obtiveram a porcentagens de inibição estaticamente semelhantes entre si, para os extratos hexânicos os percentuais de inibição dos são de valores superiores apresentando uma variação maior de intervalos estatísticos.

Os extratos hexânicos não apresentaram inibição, mas aumentaram a ação da tirosinase, com valores de 330 e $109 \%$, possivelmente devido ao fato de fornecerem substâncias fenólicas capazes de atuarem como substrato para a enzima tirosinase. O ácido kójico inibiu completamente a enzima,

Rev. Bras. PI. Med., Campinas, v.17, n.4, p.521-527, 2015. 
TABELA 3. Atividade de ativação/inibição dos extratos vegetais sobre tirosinase.

\begin{tabular}{lc}
\hline Amostra & \% inibição/ativação (60’) \\
\hline Enzima pura & $100 \mathrm{a}$ \\
Enzima + MUFM & $66 \pm 2 \mathrm{c}$ \\
Enzima + MUCM & $42 \pm 8 \mathrm{c}$ \\
Enzima + MUFH & $330 \pm 11 \mathrm{~b}$ \\
Enzima + MUCH & $109 \pm 18 \mathrm{a}$ \\
Enzima + ácido kójico & $-2 \pm 1 \mathrm{~d}$ \\
\hline
\end{tabular}

Os valores expressam a média e o desvio padrão de três repetições.. Letras minúsculas idênticas indicam equivalência estatística ao nível de $1 \%$ de probabilidade $(p<0,01)$.

Legenda: MUFM ( $M$. urundeuva folhas metanol), MUCM ( $M$. urundeuva cascas metanol), MUFH (M. urundeuva folhas hexano) e MUCH (M. urundeuva cascas hexano).

conforme esperado, pois constitui um inibidor comercial da tirosinase.

Atualmente, diversos estudos epidemiológicos mostram que os compostos fenólicos constituem uma das classes mais abundantes do reino vegetal, e possuem múltiplos efeitos biológicos (Rao, 2003). Mostrando assim que a inibição ocorre possivelmente devido ao extrato metanólico apresentar quantidades significativas de compostos fenólicos, que por possuírem uma estrutura semelhante a da tirosina, que é um substrato da enzima, se apresenta como substrato alternativo a enzima, entretanto, não sendo oxidados e competindo, desta forma, com a tirosina.

Nesse sentido, a identificação de espécies do bioma Cerrado com atividade inibitória da enzima tirosinase poderá contribuir para o desenvolvimento de novos medicamentos que possam substituir efetivamente os compostos sintéticos encontrados no mercado, melhorando a qualidade de vida de pessoas com hiperpigmentação da pele.

\section{CONCLUSÃO}

Os extratos metanólicos das folhas e cascas do caule de $M$. urundeuva apresentaram conteúdos significativos de fenóis totais, enquanto que os extratos com solvente hexano não apresentaram teores significativos destes compostos.

A atividade antioxidante está presente nos extratos metanólicos da casca de $M$. urundeuva indicando a possibilidade de existência de atividades bactericida e antiinflamatória dos compostos. Devido á presença de compostos secundários com atividade antioxidante nos extratos polares das folhas e cascas os mesmos foram submetidos á análise de atividade de ativação/inibição sobre tirosinase, apresentando resultados de inibição da mesma.

Por se tratar de extratos brutos, existem inúmeras substâncias que podem ser responsáveis por tal capacidade, por isso, os resultados descritos neste trabalho estimulam a continuidade dos estudos dos compostos presentes nas amostras obtidas, com a intenção de isolar e identificar as substâncias responsáveis pela ação antioxidante e inibidora da enzima tirosinase.

\section{AGRADECIMENTOS}

Os autores agradecem ao Conselho Nacional de Desenvovimento Científico e Tecnológico (CNPq), à Coordenação de Aperfeiçoamento de Pessoal de Nível Superior (CAPES) e ao Instituto Federal de Educação, Ciência e Tecnologia Goiano (IFGoiano) pelo apoio concedido.

\section{REFERÊNCIAS}

ALMEIDA, S.P.; PROENÇA, C.E.B.; SANO, S.M.; RIBEIRO, J.F. Cerrado: espécies vegetais úteis. Planaltina-DF: Embrapa-CPAC, 1998. 188p.

ANDRADE, M.W. et al. Micropropagação da AroeiraPreta (Myracrodruon urundeuva Fr. All.). Ciência e Agrotecnologia, v. 24, p. 174-180, 2000.

ANDO, $\mathrm{H}$. et al. Approaches to identify inhibitors of melanin biosynthesis via the quality control of tyrosinase. Journal of Investigative Dermatology, v.127, p. 751761, 2007.

BOISSY, R.E.; MANGA, P. On the etiology of contact/ occupational vitiligo. Pigment Cell Research. v. 17, p. 208-214, 2004.

BORLAUG, N.E. Feeding a world of 10 billion people: the miracle ahead. 2002. In: R. Bailey (ed.). Global warming and other eco-myths. EUA: Competitive Enterprise Institute, Roseville, EUA, p. 29-60.

CARVALHO, P.E. Espécies arbóreas brasileiras. Brasília-DF: Embrapa, 2003. 1039p.

CECÍLIO, B. A., et al. Screening of Brazilian medicinal plants for antiviral activity against rotavirus. Journal of Ethnopharmacology, v. 141, p.975-981, 2012.

CHANG, T. An Updated Review of Tyrosinase Inhibitors. International Journal of Molecular Sciences, v.10, p.2440-2475, 2009.

CROZIER, A., et al. . Dietary phenolics: chemistry, bioavailability and effects on health. Natural Product Reports, v. 26, p. 1001-1043, 2009.

HATAMNIA, A. A., et al. Antioxidant activity and phenolic profile of different parts of Bene (Pistacia atlantica subsp. kurdica) fruits. Food Chemistry, v. 145, p. 306311, 2014.

JUNIOR, T. Z. A., et al. Phenolic composition, antioxidant properties, and white cranberry fruits. Food Chemistry, v 157, p.540-552, 2014.

KHATIB, S. et al. Chalcones as potent tyrosinase inhibitors: the importance of a 2, 4-substituted resorcinol moiety. Bioorganic \& Medicinal Chemistry. v. 13, p. 433-441,

Rev. Bras. PI. Med., Campinas, v.17, n.4, p.521-527, 2015. 
2005.

KOLEVA, I.I. et al. Screening of plant extracts for antioxidant activity: a comparative study on three testing methods. Phytochemistry Analysis, v. 13, p. 8-17, 2002.

LACHMAN, J. et al. Evaluation of antioxidant activity and total phenolics of selected Czech honeys. Food Science and Technology, v.43, p. 52-58, 2010.

LARRAURI J.A. et al. Measurement of health promoting properties in fruit dietary fibres: Antioxidant capacity, fermentability and glucose retardation index. Journal Science Food Agriculture, v. 71, p. 515-519, 1996.

LORENZI, H. Árvores brasileiras: manual de identificação e cultivo de plantas arbóreas nativas do Brasil. Nova Odessa-SP: Plantarum, 1992. 368p.

MACRINI, D. J. et al. Extracts from Amazonian plants have inhibitory activity against tyrosinase : an in vitro evaluation. Brazilian Journal of Pharmaceutical Sciences, $\quad$ v. 45, n. 2, p. 715-721, 2009.

MATOS, J.F.A. Fármacias vivas: sistemas de utilização de plantas medicinais projetado para pequenas comunidades. $4^{a}$ ed. Fortaleza: UFC, 2002. 267p.

MELO, E. A.; MACIEL, M. I. S.; LIMA, V. L. A. G.; LEAL, F. L. L., CAETANO A. C. S., NASCIMENTO, R. J. Capacidade antioxidante de hortaliças usualmente consumidas. Ciência e Tecnologia de Alimentos, v. 26, n.3, p. 639-644, jul.-set. 2006.

OKOMBI S. et al. Analogues of $\mathrm{N}$-hydroxycinnamoylphenalkylamides as inhibitors of human melanocyte-tyrosinase. Bioorganic \& Medicinal Chemistry Letters, v.16, n. 8, p. 22522255, 2006.

OKUDA, T.; ITO, H. Tannins of Constant Structure in Medicinal and Food Plants: Hydrolyzable Tannins and Polyphenols Related to Tannins. Molecules, n.3, p. 2191-2217, 2011.

PASSERON, T. et al. Genetic disorders of pigmentation. Clinical Dermatology, v. 23, p. 56-57, 2005.

PAULA-JUNIOR, W. et al. Leishmanicidal, antibacterial and antioxidant activities of Caryocar brasilience Cambess leaves hydroethanolic extract. Revista Brasileira de Farmacognosia, v.16, p.625-30, 2006.

PRIOR, R. L. et al. Antioxidant capacity as influenced by total phenolics and anthocyanin content, maturity, and variety of Vaccinum species. Journal of Agricultural and Food Chemistry, v.46, n. 7, p. 2686-2693, 1998.

QUEIROZ, C.R.A.A. et al. Caracterização dos taninos da aroeira-preta (Myracrodruon urundeuva). Revista Árvore, v. 26, n. 4, p. 485-492, 2002.

$\mathrm{RAO}, \mathrm{B}$. Bioactive phytochemicals in Indian foods and their potential in health promotion and disease prevention. Asia Pacific Journal of Clinical Nutrition, v.12, p. 9-22, 2003.

SÁNCHEZ-FERRER, A. et al. Tyrosinase: Acomprehensive review of its mechanism. Biochimica et Biophysica Acta (BBA) - Protein Structure and Molecular Enzymology, v. 1247, n. 1, p. 1-11, 1995.

SCHERER, R., GODOY. Effects of extraction methods of phenolic compounds from Xanthium strumarium L. and their antioxidant activity, Revista Brasileira de Plantas Mediicinais, v. 16, n, 1, p. 41-46, 2014.

SOUSA, F.C.F. et al. Plantas medicinais e seus constituintes bioativos: uma revisão da bioatividade e potenciais benefícios nos distúrbios da ansiedade em modelos animais. Revista Brasileira de Farmacognosia, v.18, n.4, p. 642-654, 2008.

SOUSA, P.M. Atividade de inibição enzimática por espécies vegetais do bioma Cerrado. 2011. 90p. Dissertação (Mestrado - Área de Concentração em Ciências da Saúde) - Departamento de Ciências da Saúde, Universidade de Brasília, Brasília, DF.

VICENTE, S.J.V., et al. Stability of phenolic compounds and antioxidant capacity in regular and decaffeinated coffed, Brazilian Archives of Biology and Technology., v. 57, n. 1, p. 110-118, 2014.

WANG, S. Y.; LIN, H. S. Antioxidant activity in fruits and leaves of blackberry, raspberry, and strawberry varies with cultivar and developmental stage. Journal of Agricultural and Food Chemistry., v. 48, n. 2, p. 140146, 2000. 